\title{
Continuidad y radicalización del neoextractivismo en Argentina
}

\author{
Maristella Svampa* \\ Enrique Viale Trazar**
}

\begin{abstract}
RESUMEN
El (neo)extractivismo es una categoría de gran actualidad y capacidad explicativa que recorre tanto las ciencias sociales críticas en América Latina como la gramática política de diferentes movimientos socioterritoriales y organizaciones indígeno-campesinas. Podemos caracterizar al mismo como un patrón de acumulación basado en la sobreexplotación de bienes naturales, cada vez más escasos, en gran parte no renovables, así como por la expansión de las fronteras de explotación de territorios antes considerados como improductivos. La intensificación de una dinámica mercantilizadora está asociada al metabolismo social, el que en el marco del capitalismo avanzado exige para su funcionamiento cada vez más materia y energía, presionando por ende sobre bienes naturales y territorios. Argentina y un conjunto importante de países de América Latina en el presente experimentan una intensificación del (neo)extractivismo.
\end{abstract}

Palabras clave: neoextractivismo, territorio, sobreexplotación, bienes naturales, energía

\begin{abstract}
The (neo) extractivism is a category of great actuality and explanatory capacity that runs both the critical social sciences in Latin America and the political grammar of different socio-territorial movements and indigenous-peasant organizations. We can characterize it as a pattern of accumulation based on the overexploitation of increasingly scarce, largely non-renewable, natural goods, as well as the expansion of the frontiers of exploitation of previously unproductive territories. The intensification of a mercantile dynamics is associated with social metabolism, which in the framework of advanced capitalism requires for its operation more and more matter and energy, thus pressing on natural assets and territories. Argentina and an important group of countries of Latin America in the present experience an intensification of (neo) extractivism.
\end{abstract}

Keywords: Neoextractivism, territory, overexploitation, natural assets, energy

*maristellasvampa@yahoo.com

**enriqueviale@yahoo.com.ar 
1 (neo)extractivismo es una categoría de gran actualidad y críticas en América Latina como la gramática política de diferentes movimientos socioterritoriales y organizaciones indígenocampesinas. Podemos caracterizar al mismo como un patrón de acumulación basado en la sobre-explotación de bienes naturales, cada vez más escasos, en gran parte no renovables, así como por la expansión de las fronteras de explotación de territorios antes considerados como improductivos. La intensificación de una dinámica mercantilizadora está asociada al metabolismo social, el que en el marco del capitalismo avanzado exige para su funcionamiento cada vez más materia y energía, presionando por ende sobre bienes naturales y territorios. En consecuencia, el extractivismo actual se caracteriza por la exportación de bienes primarios a gran escala, entre ellos, hidrocarburos (gas y petróleo), metales y minerales, productos ligados al nuevo paradigma agrario, entre otro.

Otro rasgo inherente al neoextractivismo refiere al gigantismo o la gran escala de los emprendimientos, la cual nos advierte también sobre la envergadura de las inversiones (de carácter capital-intensivo y no trabajo-intensivos) y de los actores intervinientes -en general, corporaciones transnacionales. Asimismo, desarrolla una dinámica territorial cuya tendencia es la ocupación intensiva del territorio y el acaparamiento de tierras, a través de formas ligadas al monocultivo o monoproducción. El avance sobre el territorio combina, en gran parte de los casos, la dinámica del enclave o de la fragmentación territorial (escasa producción de encadenamientos endógenos relevantes), con la dinámica del desplazamiento (dislocación de las economías locales tradicionales y expulsión de poblaciones).

Por último, más allá de las ventajas comparativas (altos precios internacionales de los commodities), en sus diferentes formas, la dinámica extractiva inserta a los países del sur como proveedores de materias primas, reformulando una vez más las históricas asimetrías entre el centro y la periferia, en el marco de la división internacional del trabajo, tal como aparece reflejado en la distribución desigual de los conflictos socioambientales y en la reprimarización de las economías. 
Así definido, el neoextractivismo abarca algo más que aquellas actividades consideradas tradicionalmente como extractivas. Además de la megaminería a cielo abierto, incluye la expansión de la frontera petrolera y energética (a través de la explotación de gas y petróleo no convencional, con la tan cuestionada metodología de la fractura hidráulica o fracking), la construcción de grandes represas hidroeléctricas (en general, al servicio de la actividad extractiva), la expansión de la frontera agrícola y la generalización del modelo de agronegocio, la expansión de la frontera pesquera (ligados a la sobreexplotación y sobrepesca) y forestal.

En América Latina, la expansión del neoextractivismo se insertó en un contexto de cambio de época, marcado por el pasaje a un escenario político-económico en el cual una de las notas mayores es el Consenso de los Commodities, que comparten los diferentes gobiernos, independientemente de su orientación ideológica. Ciertamente, a diferencia de los años '90, a partir del año 2000-2003, las economías latinoamericanas se vieron favorecidas por los altos precios internacionales de los productos primarios (commodities), lo cual se vio reflejado en las balanzas comerciales y el superávit fiscal. En esta coyuntura de rentabilidad extraordinaria (al menos, hasta 2013), los gobiernos latinoamericanos tendieron a subrayar las ventajas comparativas del boom de los commodities, negando o minimizando las nuevas desigualdades y la explosión de conflictos socioambientales y territoriales inherentes a la inflexión extractivista.

\section{LA EXPANSIÓN DEL NEOEXTRACTIVISMO DURANTE EL CICLO}

\section{KIRCHNERISTA}

En esta línea, en Argentina, los gobiernos de Néstor Kirchner (20032007), el de Cristina Fernández de Kirchner (2007-2015) y, en la actualidad, el de Mauricio Macri (2015-), habilitaron el retorno en fuerza de una visión productivista del Desarrollo, asociada a la expansión del extractivismo, negando o escamoteando las discusiones de fondo acerca de las implicancias (impactos, consecuencias, daños) en torno los diferentes modelos extractivos, y minimizando los cuestionamientos y el alcance de las protestas socioambientales. 
En nuestro país, el neoextractivismo aparece básicamente ilustrado por la expansión de la frontera sojera, la megaminería a cielo abierto, los hidrocarburos no convencionales, las megarepresas y la fuerte tendencia al acaparamiento de tierras. Sin embargo, aunque presentan una lógica en común, estas actividades poseen características específicas y están ligados a diferentes imaginarios del desarrollo.

-Megaminería. Desde 2003 en adelante, la expansión de la megaminería a cielo abierto generó numerosas resistencias sociales. Tal es así que, en su alianza con actores institucionales, las asambleas ciudadanas que fueron emergiendo al calor de las luchas, lograron la sanción de diferentes leyes que prohíben este tipo de minería en siete provincias. Pese a que el kirchnerismo pudo mantener dichas protestas encapsuladas a nivel local, hecho favorecido por la provincialización de los recursos naturales, la megaminería fue un punto crucial donde naufragó el discurso progresista.

En enero de 2012, se produjo la pueblada de Famatina, una pequeña localidad de la provincia de La Rioja, hecho que contribuyó a dar mayor visibilidad este tipo de conflictos. La periferia se hizo visible en el centro, y al menos por un tiempo breve, las protestas contra la megaminería tuvieron un eco a nivel nacional. Frente a ello, a la hora de abordar la cuestión, la entonces presidenta Cristina de Kirchner dejó en claro que la minería era una parte fundamental del modelo de desarrollo. Sin embargo, la pueblada de Famatina tuvo un efecto político y simbólico mayor, al desnudar las alianzas del gobierno con la minería transnacional. Posteriormente los diferentes derrames de solución cianurada en la mina de Veladero (2015 y 2016), emprendimientos a cargo de la compañía canadiense Barrick Gold, pusieron al descubierto el carácter insustentable de la actividad, al tiempo que dinamizaron las resistencias en diferentes provincias, sobre todo en San Juan.

-El AGRONEGOCios, y especialmente la soja transgénica, ocupa sin duda el corazón del modelo extractivo argentino. En la actualidad, la Argentina se encuentra entre los cuatro principales productores 
mundiales de soja, con 23,9 millones de hectáreas cultivadas. Desde fines de los años 90, la expansión del agronegocios implicó una restructuración global del sistema agrario tradicional (lógica de ganadores y perdedores), pese a lo cual hubo una gran dificultad en abrir un debate social, político y ambiental sobre sus implicancias. Uno de las cuestiones que obtura cualquier discusión seria es que, más allá de los poderosos lobbies económicos, existe en nuestro país un imaginario social de bonanza y crecimiento económico, asociado históricamente al modelo agro-exportador.

Por otro lado, el modelo de agronegocios presenta mayor complejidad que otros sistemas extractivos (por ejemplo, la megaminería), debido a su capacidad para articular actores sociales y económicos diferentes, así como también por la red de empleos y servicios que genera. Sin embargo, esta trama socioproductiva no puede ocultar la presencia de cuatro elementos que delatan su carácter extractivo y la insustentabilidad social y ambiental, asociada al mismo. Primero, la orientación a la exportación, disociada de cualquier preocupación por la soberanía alimentaria. Segundo, la fuerte tendencia al monocultivo de la soja, lo cual conlleva mayor deforestación, pérdida de biodiversidad, acaparamiento de tierras, expulsión de poblaciones y un incremento de la criminalización y asesinatos de campesinos e indígenas. Tercero, este proceso está ligado también al acaparamiento de tierras -en inglés land grabbing-, visible en las actividades concentradas (soja, maíz, cańa de azúcar), con una alta presencia de inversión extranjera y de pools de siembra. Cuarto, los impactos negativos sobre la salud de las personas, a raíz de la utilización masiva de glifosato, a través de las fumigaciones, son cada vez más insoslayables.

-EXPLOTACIÓN HIDROCARbURÍFERA. El neoextractivismo aparece asociado a la explotación hidrocarburífera, muy especialmente a la explotación de hidrocarburos no convencionales a través del fracking. Recordemos que en 2010, en un contexto de restricción interna y externa, la empresa Yacimientos Petrolíferos Fiscales, en ese entonces en mano del grupo español Repsol, anunció el descubrimiento 
de hidrocarburos no convencionales en la formación geológica de Vaca Muerta, ubicado en la región Patagónica. En 2012 el gobierno kirchnerista realizó la expropiación parcial (51\% de las acciones) de YPF, que volvió así a manos del Estado argentino, y dio inicio a un conjunto de transformaciones institucionales y políticas, planteando entre sus principales objetivos la explotación de hidrocarburos no convencionales como una manera de impulsar al conjunto de la producción nacional. A través de la figura de la sociedad mixta se colocó en el centro del nuevo paradigma la búsqueda y otorgamiento de grandes concesiones a los capitales extranjeros, tal como ya se hizo con Chevron (condenada en Ecuador por graves delitos ambientales y violación de derechos indígenas. cuando era Texaco), otorgándole grandes exenciones y beneficios en la explotación de hidrocarburos no convencionales, en la Cuenca del Neuquén.

En suma, la vuelta de tuerca privatista dejó muy lejos el modelo nacional-estatal que fuera reivindicado -al menos retóricamente- a la hora de la intervención de Repsol-YPF. Sin embargo, el gobierno logró instalar una suerte de "consenso sobre el fracking", que asociaría de modo lineal producción de combustibles fósiles con soberanía energética. En dicho contexto se tornó muy complicado cuestionar el fracking, aun invocando el carácter controversial que éste tiene en otros países, donde se ha declarado la moratoria o ha sido prohibido (Alemania, Francia, diferentes estados de Estados Unidos y Canadá, entre otros), o incluso apelando a los informes sobre las consecuencias socioambientales y sanitarias que su implementación ya ha generando en Estados Unidos. Hubo cuestionamientos -organizaciones ambientales, asambleas y pueblos originarios, colectivos de intelectuales- pero éstos permanecieron en la periferia, ignorados en medio de la euforia eldoradista promovida por el gobierno.

Hacia el fin de ciclo kirchnerista, en un contexto de baja de los precios internacionales de los hidrocarburos, otro aspecto relevante fue el subsidio estatal a las compañías petroleras, a fin de mantener el empleo en el sector. Al mismo tiempo, la caída del precio del crudo, motivó la paralización de numerosos proyectos de explotación en Vaca Muerta. 
-ACAPARAMIENTO DE TIERRAs. La expansión vertiginosa de las fronteras del capital, en clave extractivista, muestra el creciente proceso de arrinconamiento de los pueblos originarios, colocados en la periferia de la periferia. En 2006, a demanda de las organizaciones y en un contexto de creciente conflictividad, se sancionó la ley 26.160, que prohíbe los desalojos de las comunidades indígenas y ordena la realización de un relevamiento territorial. Sin embargo, este ordenamiento jurídico que se despliega en diferentes niveles (provincial y nacional, siguiendo una normativa internacional), contrasta con la realidad. El Informe final del relator sobre los pueblos indígenas de la ONU, James Anaya, quien visitó la Argentina en 2011, para recoger testimonios y denuncias de las comunidades, muestra un cuadro muy preocupante donde se subraya el impacto ambiental y cultural, la fragmentación del tejido social, la falta de consulta previa (Convenio 169 de la OIT), los desalojos violentos, las situaciones de criminalización y represión, entre otros.

Asimismo, tal como afirma el Observatorio de Derechos Humanos de los Pueblos Indígenas (ODHPI), la criminalización de los pueblos originarios no se ha dado tanto en el ejercicio del legítimo derecho de protesta, sino cuando se hace uso de derechos reconocidos jurídicamente (reclamo de tierras y territorios, cuyos derechos se hayan amparados por la normativa nacional y provincial existente). Los datos proporcionados por un informe realizado por Encuentro Memoria, Verdad y Justicia, de 2012 sobre criminalización de la protesta según sector, son alarmantes. Un relevamiento sobre 2198 casos, ocurridos entre 2001 y 2012, señala que el 31,4\% del total corresponde a los pueblos originarios, esto es, casi un tercio del total, equiparando éste al sector de las luchas sindicales.

A esto hay que agregar que el creciente acaparamiento de tierras así como la especulación inmobiliaria en las ciudades trajo consigo el aumento de los asentamientos urbanos (villas miseria). Por ejemplo, solamente en la ciudad de Buenos Aires, entre 2003 y 2013, la población en asentamientos aumentó un 50\%. Dicha población, convertidas en el blanco de las "políticas de seguridad" de los gobiernos 
nacionales y municipales es también la sede de nuevos movimientos socio-territoriales, que se movilizan constantemente en las ciudades en demanda de tierra y vivienda.

En suma, durante el kirchnerismo, asistimos a la paradójica disociación de las agendas de derechos humanos, una, abocada a la temática del terrorismo de Estado y los crímenes de lesa humanidad; otra, ligada a los impactos del neoextractivismo en los diferentes territorios. Este hiato entre ambas agendas fue potenciado por la desconexión existente entre luchas sindicales y luchas contra el extractivismo. Pero en líneas generales la relación directa entre neoextractivismo, política de concentración de la tierra y deterioro de los derechos fue un punto ciego del progresismo kirchnerista y, salvo raras excepciones, de las organizaciones de derechos humanos ligadas al gobierno. En este marco, no es casual que el kirchnerismo mantuviera blindado el discurso progresista, frente al carácter estructural de estas problemáticas, negando la responsabilidad del gobierno nacional, subrayando, en contraste, el peso determinante de las políticas sociales y la revitalización de institutos laborales, como la negociación colectiva, entre otros.

\section{LA RADICALIZACIÓN DEL NEOEXTRACTIVISMO}

En sus dos primeros años de gestión, el gobierno de Mauricio Macri mostró rupturas pero también continuidades respecto de la gestión saliente. En términos de rupturas, están aquellas de tipo ideológico: a partir de diciembre de 2015, la Argentina dejó de ser gobernada por un régimen identificado con un populismo progresista de alta intensidad, para pasar a manos de una derecha aperturista, de tipo empresarial, basada en el modelo de la "comunidad de negocios", que no desdeña el trabajo territorial y pretende reducir la política a la gestión y el marketing.

Respecto del neoextractivismo, el gobierno de Macri avanzó sobre varios frentes, aunque sin un discurso vergonzante. Eliminó las ya exiguas retenciones a la minería y disminuyó las de la soja, transfirió la secretaría de minería al nuevo Ministerio de Energía y Minería, a cargo del ex CEO de Shell, creó un Ministerio del Ambiente, donde 
nombró alguien que confiesa no saber nada del tema, y reforzó la figura de la Organización Federal de Estados Mineros (OFEMI), creada por el kirchnerismo en 2012. Asimismo continúa con el subsidio a las petroleras, sector donde avanzó con un convenio de flexibilización laboral, para impulsar las inversiones. Al mismo tiempo, comenzó a hablar de "cuidado del ambiente" y de "participación ciudadana", aunque en realidad, dicha narrativa es una fórmula vacía, más ligada al discurso hegemónico de la Modernización ecológica, con unos pocos slogans efectistas, antes que a una propuesta de discusión integral sobre los actuales modelos de desarrollo. Ciertamente, el nuevo oficialismo despliega una idea hiperdébil de la sustentabilidad, tal como lo muestra la inversión en ecología y ambiente prevista en el presupuesto de 2017, la que alcanza apenas del 0,5\%.

En los últimos tiempos se ha hecho manifiesto un plan sistemático para flexibilizar la escasa normativa de protección ambiental existente, lograda gracias a movilizaciones populares y múltiples acciones de la sociedad civil. Estamos asistiendo a una suerte de "trumpización" de la política ambiental, pues no se trata de hechos aislados e inconexos, sino de procedimientos metódicos y premeditados, de modo similar al de la actual gestión norteamericana. En este marco se inscribe el intento del Gobierno Nacional de una nueva reglamentación -vía decreto- de la Ley Nacional de Glaciares, con el objetivo de reducir notablemente las áreas protegidas. Una reforma a medida de las compañías mineras que, como la Barrick Gold, realizan su actividad sobre glaciares y periglaciales, algo explícitamente prohibido por la ley sancionada en 2010.

En sintonía con la quita total de las retenciones mineras, el oficialismo promueve un Nuevo Acuerdo Federal Minero, que -entre otras cosas- apunta a debilitar las regulaciones ambientales en las provincias donde existe resistencia social a dicha actividad, con el objeto de atraer capitales. En esta línea, ha iniciado una campaña internacional: así, en marzo de 2017, mientras en una importante feria minera en Canadá el gobierno hacía circular un "folleto minero" ofertando yacimientos situados en provincias donde la megaminería está prohibida por leyes locales, en Inglaterra, el actual ministro de 
economía, N. Dujovne promovía la megaminería metalífera y del litio.

Iniciativas similares alcanzan la Ley Nacional de protección de los Bosques Nativos. Así, en la provincia de Buenos Aires la gobernadora María Eugenia Vidal logró sancionar una ley que "ordena" el bosque nativo provincial, que encaja perfectamente con los intereses inmobiliarios y el agronegocio (recordemos que el actual Secretario Provincial de Agroindustria es un ex alto directivo de Monsanto). Una norma regresiva que funcionó como termómetro en la ya inocultable intención del gobierno de desvirtuar hasta aniquilar la Ley Nacional de Bosques. La próxima en sufrir un (re)ordenamiento provincial a medida del agronegocio sería la provincia de Córdoba, donde se han registrado masivas movilizaciones -de más de 30 mil personaspara defender el limitado 3\% de bosque nativo que dicha provincia conserva de sus formaciones originales.

Por la vía del decreto, fue modificada la Ley Nacional de Tierras Rurales que establecía limitaciones a la tenencia de tierras por parte de extranjeros, lo que favorece a amigos del Presidente, como el magnate inglés Joe Lewis, quien además de tener secuestrado un lago público, pretende desarrollar un emprendimiento inmobiliario en áreas protegidas, pese a que la comunidad de El Bolsón y otras aledañas han manifestado su rechazo con grandes movilizaciones y acampes. Asimismo, el Gobierno Nacional anunció el relanzamiento de la explotación en Vaca Muerta, que supone no sólo flexibilización ambiental sino también laboral, para hacer rentable la costosísima y tan controversial técnica de fractura hidráulica.

Por otro lado, el Proyecto de Ley de Protección de Humedales, cuenta con el boicot sistemático del oficialismo nacional, producto del lobby conjunto de sectores inmobiliarios, agronegocio y minería, a pesar de que las cada vez más recurrentes inundaciones muestran hasta qué punto los humedales son imprescindibles y estratégicos, en tanto ecosistemas, para la regulación hídrica.

En suma, si bien que el discurso de Macri alude al cuidado del medio ambiente y promueve las energías renovables, los contundentes ejemplos citados evidencian todo lo contrario. Así, en nombre de 
la "modernización ecológica" el actual gobierno apuesta a ampliar el poder de las grandes corporaciones a través de la flexibilización ambiental, anticipando con ello un contexto de grave regresividad de derechos. Que esto se haga hablando de "cambio climático" o de la importancia de las energías renovables no es un matiz, sino más bien una pantalla, con la cual se intenta maquillar la radicalización del neoextractivismo en nuestro país.

Por último, hay que destacar la acumulación de luchas, visible en un incremento de la conflictividad socio-ambiental y territorial en las periferias, cuya presencia en la agenda nacional, aunque transitoria y fugaz, es más relevante que en los años anteriores. Sin embargo, aún si en la actualidad se registra una conexión mayor entre la conflictividad social-urbana y la socio-ambiental, esto es, entre centros y periferias, en un marco de empobrecimiento general de la población y de temor a la recesión, existe el peligro de que asistamos a una unidimensionalización de las resistencias, priorizando las acciones reivindicativas (sindicales, territoriales), e invisibilizando las resistencias socioambientales a las diferentes formas de neoextractivismo en nuestro país.

Fecha de Recepción del Artículo: 19 de mayo de 2017 Fecha de Aceptación: 16 de junio de 2017 